\title{
Silicone oil removal: post-operative complications
}

\author{
Reda Issa $\mathbb{D}^{1} \cdot$ Tian Xia $^{1} \cdot$ Marco A. Zarbin ${ }^{1} \cdot$ Neelakshi Bhagat $^{1}$
}

Received: 12 December 2018 / Revised: 1 May 2019 / Accepted: 11 July 2019 / Published online: 12 August 2019

(c) The Author(s), under exclusive licence to The Royal College of Ophthalmologists 2019

\begin{abstract}
Purpose To describe the characteristics, outcomes and complications of eyes after silicone oil removal.

Methods Retrospective case series of eyes that underwent oil removal between 2012 and 2016 at The Institute of Ophthalmology and Visual Science. Visual acuity (VA), intraocular pressure (IOP) and rates of retinal re-detachment, hypotony, ocular hypertension, corneal decompensation, cystoid macular edema (CME) and cataract progression were evaluated.

Results Totally, 101 eyes of 99 patients ( $65 \%$ male, average age 47.2 years) were identified. Oil tamponade had been used for retinal detachment (RD) repair in all eyes; 15 eyes had also undergone an open globe repair previously. The most common vitreous substitutes used after oil removal were balanced salt solution (BSS) and air in $90 \%$ of eyes. The average time of oil tamponade before removal was 9.46 months. The average logMAR VA before oil removal was 1.7 which improved to an average of 1.4 post-operatively. The average IOP pre-operatively was $16.1 \mathrm{~mm} \mathrm{Hg}$, which decreased to an average of $14.8 \mathrm{~mm} \mathrm{Hg}$ post-operatively. Complications after oil removal, included retinal re-detachment (6.9\%), hypotony (7.9\%), ocular hypertension (12.9\%), corneal decompensation (9.9\%), CME (2\%) and cataract progression (68\%).

Conclusion This study showed an overall improvement in VA and decrease in IOP after oil removal. Cataract progression was the most common complication.
\end{abstract}

\section{Introduction}

Silicone oil (SO) was introduced in retina surgery by Cibis et al. [1,2] who reported a series of 33 eyes in which SO was used as vitreous substitute in 1962 [3]. Its use was popularised much later in 1970s with the advent of pars plana vitrectomy and was approved by US Food and Drug Administration for intraocular use in 1997.

SO tamponade has become a standard technique for repair of complex retinal detachments (RDs) [4-14] with giant retinal tears, proliferative vitreoretinopathy (PVR) [4-9], viral retinitis and ocular trauma [15]. It is considered a better internal tamponade than sulphur hexafluoride gas $\left(\mathrm{SF}_{6}\right)$ in eyes with advanced PVR, both for anatomic and functional success $[16,17]$. However, silicone oil can lead to long-

Presentation: New York Academy of Medicine. Poster presentation. Manhattan, NY. May 21, 2018.

Neelakshi Bhagat

bhagatne@njms.rutgers.edu

1 Institute of Ophthalmology and Visual Science, Rutgers-New Jersey Medical School, Newark, NJ, USA term complications, particularly glaucoma and keratopathy, which limits its use to the most severe cases. Another important consideration in the use of SO is the need for an additional surgical procedure to remove the oil once stable retinal anatomic status is achieved. Oil removal also is associated with a risk of recurrent RD. The purpose of this retrospective study is to describe and analyse the outcomes and complications in eyes after SO removal at our institution.

\section{Methods}

This is a retrospective case series of eyes that underwent $\mathrm{SO}$ removal between January 2012 and June 2016 at the Institute of Ophthalmology and Visual Science, RutgersNew Jersey Medical School, in Newark, NJ. This study was approved by the institution's investigational review board. Patients whose complete records could not be located were excluded. Only cases that had two or more months of follow up were included.

Preoperative and postoperative data, including visual acuity (VA), slit-lamp examination and fundus findings, intraocular pressure (IOP) measured by Goldman applanation tonometry or Tonopen and optical coherence tomography 
(OCT) results were recorded for analysis. Hypotony was defined as IOP less than $6 \mathrm{~mm} \mathrm{Hg}$ on two or more occasions. Lens opacity was recorded as $0-4+$ in three main categories-nuclear sclerosis, posterior subcapsular cataract and cortical cataract [18]. Details of original RD repair surgery, type of oil used, techniques used and details of SO removal surgery were recorded. The Snellen chart for VA measurement was used and converted to the logarithm of the minimum angle of resolution (logMAR) for quantitative analysis. Other variables, IOP, VA, onset of retinal redetachment, hypotony, ocular hypertension, corneal decompensation, cystoid macular edema (CME) and cataract progression were recorded at different time intervals. Surgical procedures were performed by two retinal surgeons (NB and MZ) at University Hospital in Newark, NJ. Hypotony is defined as IOP $<6 \mathrm{~mm} \mathrm{Hg}$ measured on two or more office visits. Elevated IOP was defined as a maximal value that reached $>24 \mathrm{~mm} \mathrm{Hg}$ despite an average $<24 \mathrm{~mm} \mathrm{Hg}$, or chronically in which the average pre-op IOP was $>24 \mathrm{~mm} \mathrm{Hg}$. Data are represented as mean with standard deviation unless otherwise noted, and descriptive analysis was performed on all variables.

\section{Results}

Totally, 101 eyes of 99 patients underwent SO removal between January 2012 and June 2016. In all these cases, anatomic success had been achieved, and oil tamponade was deemed no longer necessary. The average age of the subjects was $47.2 \pm 15$ years, with 4 being under the age of 18 years. In all, 65\% were male. Types of RDs that required the use of SO tamponade were diabetic tractional retinal detachments (TRDs) $(21.7 \%)$ due to multiple stretch holes and extensive TRDs, complex rhegmatogenous retinal detachments (RRDs), including combined RRD/TRD with PVR or giant retinal tears $(53.5 \%)$ and RDs associated with globe trauma, including open globes $(24.8 \%)$.

The average duration of SO tamponade before removal was 9.46 months (Fig. 1). The oil was removed using either 20 - or 23-gauge sclerotomies. Pre-operatively (prior to SO removal), 61 eyes $(60 \%)$ were phakic, $22(22 \%)$ were pseudophakic (all posterior chamber intraocular lens) and $18(18 \%)$ were aphakic. Visually significant cataract was noted in 26 eyes (26\%) (at least $3+\mathrm{NS}$, and/or $2+\mathrm{PSC}$, or mature cataract) pre-operatively. Seven eyes $(7 \%)$ underwent pars plana lensectomy for visually significant cataract when it limited the view to the posterior segment during SO removal surgery.

Oil was noted in the anterior chamber in 12 of $101(12 \%)$ eyes, pre-operatively; emulsification of oil was noted in 10 eyes. Eight of 12 eyes with SO in the anterior chamber were
TIME TO OIL REMOVAL BYETIOLOGYOF

RD

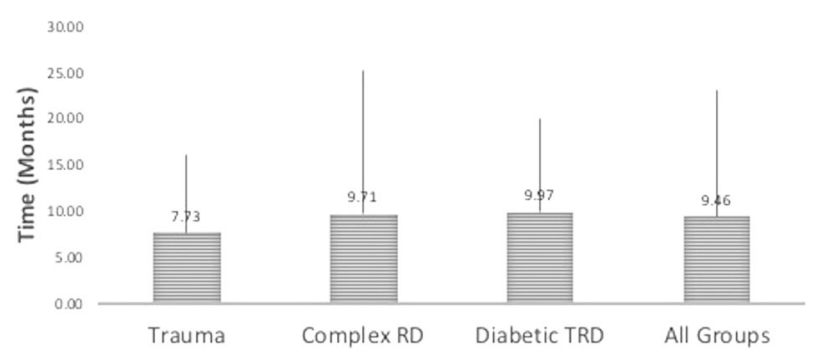

Fig. 1 Time to oil removal by aetiology of retinal detachment (RD)

aphakic $(n=4)$ or pseudophakic $(n=4)$. No phacodenesis was noted in any eye. Four eyes had corneal abnormalities: a failing PKP graft, moderate corneal stromal haze with oil in the anterior chamber, mild band keratopathy from oil in the $\mathrm{AC}$ and a nonhealing epithelial defect. The average duration of SO tamponade in these four eyes was 20.4 months.

Table 1 shows indications of oil insertion, VA and IOP data pre- and post-SO removal. Overall VA at Pre-Op, Postop month 1 , month 3 and month 6 were $1.7 \pm 0.5,1.6 \pm 0.6$, $1.6 \pm 0.6$ and $1.5 \pm 1.7$, respectively. Average pre-SO removal IOP was $16.1 \pm 5.8 \mathrm{~mm} \mathrm{Hg}$; lowest recorded preop IOP was $11.2 \pm 6.1 \mathrm{~mm} \mathrm{Hg}$; and highest recorded pre-op IOP was $23 \pm 8.4 \mathrm{~mm} \mathrm{Hg}$. In addition, the percentage of eyes that had ocular hypertension (defined as a maximal value that reached $>24 \mathrm{~mm} \mathrm{Hg}$ despite an average $<24 \mathrm{~mm}$ $\mathrm{Hg}$, or chronically in which the average pre-op IOP was $>24 \mathrm{~mm} \mathrm{Hg}$ ) was $29.7 \%$. The average final post-op IOP was $14.8 \mathrm{mmHg}$ at 6 months post-operatively. Table 2 shows the percentage of eyes with at least two lines of improvement in VA and at least $5 \mathrm{mmHg}$ in IOP in eyes with last follow up at 3, 6 and 12 months, respectively.

None of the eyes had hypotony (an average IOP $<6 \mathrm{~mm}$ $\mathrm{Hg}$ ) before SO removal, but 7 eyes (7\%) had a minimum measured IOP $<6 \mathrm{~mm} \mathrm{Hg}$, which indicates an intermittent IOP $<6 \mathrm{mmHg}$ despite an average IOP $\geq 6 \mathrm{~mm} \mathrm{Hg}$. The average VA before SO removal was $1.7 \pm 0.5$ LogMAR $(\sim 20 / 1000)$.

Vitreous substitutes used after SO removal were balanced salt solution (BSS) or air in $90 \%$ of eyes; $10(9.85 \%)$ eyes received gas tamponade $\left(\mathrm{SF}_{6} 18-20 \%\right.$ or $\left.\mathrm{C}_{3} \mathrm{~F}_{8} 12-15 \%\right)$. Half of the eyes had $360^{\circ}$ peripheral retinal laser performed during the original RD repair; 13 (13\%) eyes had an encircling scleral buckle. All eyes but one had high viscosity SO (5000 centistokes).

Figure 2 shows the distribution of post-operative complications. Additional interventions required after SO removal included two glaucoma drainage implants, three penetrating keratoplasties and one enucleation and seven PPVs. 
Table 1 Indications of SO insertion, VA and IOP pre- and post-SO removal

\begin{tabular}{llllll}
\hline $\begin{array}{l}\text { Indications of SO } \\
\text { insertions }\end{array}$ & $\mathrm{N}(\%)$ & $\begin{array}{l}\text { Pre-op VA } \\
(\operatorname{logMAR} \pm \mathrm{SD})\end{array}$ & $\begin{array}{l}\text { Pre-op IOP } \\
(\mathrm{mm} \mathrm{Hg} \pm \mathrm{SD})\end{array}$ & $\begin{array}{l}\text { Post-op VA } \\
(\log \mathrm{HAR} \pm \mathrm{SD})\end{array}$ & $\begin{array}{l}\text { Post-op IOP } \\
(\mathrm{mm} \mathrm{Hg} \pm \mathrm{SD})\end{array}$ \\
\hline OGI & $15(15)$ & $2.0 \pm 0.4$ & $12.2 \pm 4.3$ & $2.0 \pm 0.8$ & $15.3 \pm 8.6$ \\
RRD & $64(63)$ & $1.6 \pm 0.5$ & $15.7 \pm 5.1$ & $1.4 \pm 0.7$ & $15.0 \pm 5.8$ \\
TRD & $22(22)$ & $1.6 \pm 1.6$ & $17.8 \pm 8.2$ & $1.3 \pm 1.0$ & $13.8 \pm 5.0$ \\
\hline
\end{tabular}

$S O$ silicone oil, VA visual acuity, $I O P$ intraocular pressure, $O G I$ open globe injury, $R R D$ rhegmatogenous retinal detachment, TRD tractional retinal detachment
Table 2 Percentage of eyes with VA improvement by two lines and percentage of eyes with a $5 \mathrm{~mm} \mathrm{Hg}$ decrease in IOP after oil removal surgery

\begin{tabular}{lll}
\hline Months & $\begin{array}{l}\text { Percentage of eyes with VA } \\
\text { improvement of at least two } \\
\text { lines of }(\%)\end{array}$ & $\begin{array}{l}\text { Percentage of eyes with at } \\
\text { least } 5 \mathrm{~mm} \mathrm{Hg} \text { decrease in } \\
\text { IOP }(\%)\end{array}$ \\
\hline 3 & 40 & 73 \\
6 & 53 & 47 \\
12 & 59 & 81 \\
\hline
\end{tabular}

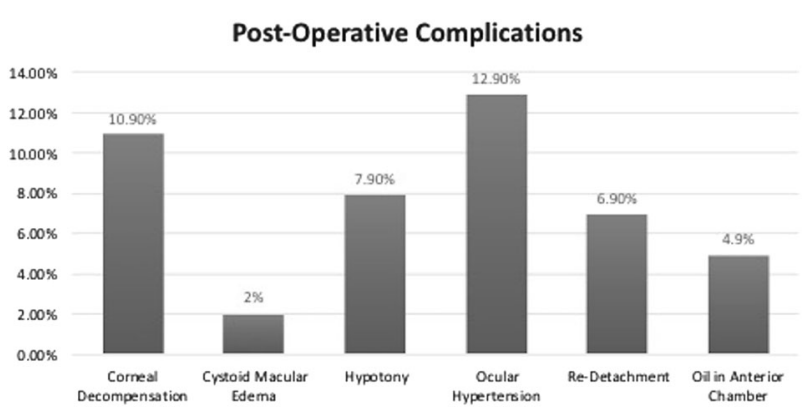

Fig. 2 Post-operative complications after SO removal

Post-operatively, corneal complications occurred in 11 (11\%) of eyes: 4 eyes had non-healing epithelial defects (1 progressed to corneal ulcer and required penetrating keratoplasty (PKP)), 2 failed PKs required repeat grafts, 2 eyes developed corneal oedema associated with ocular hypertension and 3 eyes developed band keratopathy (BK). Among the eyes with $\mathrm{BK}$, two had SO in the anterior chamber pre-SO removal and one had residual SO in the anterior chamber after SO removal $(<10 \%)$; one of the three had mild BK before SO removal. Cystoid macular edema was seen in two eyes (2\%) that had undergone RD repair; none of the patients was diabetic and none had CME preoperatively. Seven eyes (7\%) underwent PPV after SO removal: five for recurrent $\mathrm{RD}$, one for full thickness macular hole without RD and one for hypotony (and underwent two PPV for this condition).

Hypotony, defined as IOP $<6 \mathrm{~mm} \mathrm{Hg}$ on two or more occasions was observed in $8(8 \%)$ eyes after SO removal. Average IOP pre-oil removal surgery was $16.1 \mathrm{~mm} \mathrm{Hg}$. None of the eyes had an average IOP $<6 \mathrm{~mm} \mathrm{Hg}$ prior to SO removal, but 7 eyes had random measurements of IOP
$<6 \mathrm{~mm} \mathrm{Hg}$ before SO removal. Of these seven eyes, hypotony was seen in four eyes $(57 \%)$ after SO removal. The average IOP in the four eyes that had lower IOP pre-SO removal and developed hypotony, was $7.4 \mathrm{~mm} \mathrm{Hg}$. Of the eight eyes developing hypotony after SO removal, four had open globe injury, three had advanced diabetic TRD and one had RRD with PVR. Of these hypotonus eyes, three had undergone retinotomy and retinectomy: two had $360^{\circ}$ of retinotomy and retinectomy; one had a $90^{\circ}$ retinotomy. Late hypotony (i.e., onset more than 6 months after SO removal) occurred only in one case, whereas seven eyes developed hypotony immediately after SO removal that persisted until last follow-up. One eye required reinsertion of oil for hypotony management. Pre-operative average VA of these eight hypotonus eyes was finger counting. No eyes progressed to phthisis.

Ocular hypertension, defined as IOP $>24 \mathrm{~mm} \mathrm{Hg}$ on 2 or more occasions, was noted in $13(13 \%)$ of eyes after SO removal. Two had Ahmed tubes inserted eventually after maximal therapy was reached at 15.2 and 4.3 months, respectively.

Retinal re-detachment occurred in seven eyes (7\%), requiring a repeat vitrectomy with gas or oil tamponade: two were macular hole-related RDs. Recurrent RD occurred at an average of 5.6 months (range: 1-16 months) after SO removal. Five of the seven eyes that re-detached had received supplementation of demarcation laser at the time of SO removal. The indication for the initial PPV in these seven eyes included open globe injury (two eyes), diabetic TRD (one eye), combined RRD/TRD with PVR (one eye) with history of a failed PPV/gas and RRD (three eyes). Vitreous substitute used included one C3F8, one SF6 and rest with water.

One diabetic eye had new onset rubeosis after SO removal and underwent one anti-VEGF injection with rubeosis resolution.

Three eyes (3\%) underwent membrane peel at the time of SO removal. The pre- and post-SO removal visual acuities in these three eyes were CF, 20/80, HM, and HM, 20/30, $\mathrm{LP}$, respectively. The eye with final VA of LP vision developed hypotony after SO removal.

A total of $68 \%$ had cataract progression SO removal. A cataract was considered significant if lens had at least $3+$ NS or $2+\mathrm{PSC}$, or if the lens was described as mature, 
brunescent or white. Significant cataract progression was seen in 68 eyes $(68 \%)$ in our series; 8 were described as mature, including 3 white and 5 brunescent cataracts.

\section{Discussion}

SO tamponade achieves better anatomic and functional success than $\mathrm{SF}_{6}$ tamponade when used in repair of advanced complex RDs [16]; it also enables more rapid visual rehabilitation in the immediate post-operative period, relieves the need for strict face down positioning in patients with neck or back disorders and permits high altitude (e.g., air) travel [19]. SO has also been shown to decrease the risk of neovascular glaucoma, by compartmentalising proangiogenic factors, as well as tamponade recurrent vitreous haemorrhage in patients with proliferative diabetic retinopathy $[3,12,14,20]$. One of the biggest drawbacks of using $\mathrm{SO}$, however, is the need for a second procedure to remove the oil. Some clinicians recommend removing SO as quickly as possible once the retina heals to prevent oilrelated complications [14, 21]; others have shown that prolonged SO tamponade does not increase those risks significantly [22-24]. Overall, though, the most common recommendation is to remove SO within 3-6 months after insertion [25, 26], but each eye needs to be evaluated for $\mathrm{SO}$ removal on an individual basis. In this study, the average time of SO tamponade before removal was 9.46 months. This series, however, had a higher proportion of traumatic cases compared to other reports, which may have contributed to the decision to retain SO tamponade for a longer period of time. All the cases (except one) employed SO with higher viscosity, $5000 \mathrm{cs}$.

Initial rapid improvement in VA was noted during the first 6 months after SO removal, followed by a slower, progressive improvement. Only two of these eyes had cataract extraction within the first 6 months after SO removal. There was also a steep decline in IOP during the initial month after SO removal that plateaued thereafter. Some studies [27, 28] have reported significant decrease in IOP with SO removal while others have not [29]. Increased IOP and peripheral anterior synechiae formation can occur with $\mathrm{SO}$ in the anterior chamber [28].

The reported rate of recurrent $\mathrm{RD}$ after $\mathrm{SO}$ removal ranges between 0 and $33 \%$ [7, 22, 23, 25, 30-43] with majority of studies reporting in the $8-12 \%$ range. In the present study, the rate of re-detachment was $7 \%$. Recurrent $\mathrm{RD}$ was seen at an average of 5.6 months (range: 1-16 months) after SO removal. Many variables affecting re-detachment were similar between the re-detached group and the overall group, including use of $360^{\circ}$ peripheral retinal laser demarcation at the initial $\mathrm{RD}$ repair $(n=3)$, use of supplemental demarcation laser during SO removal $(n=5)$, presence of scleral buckle $(n=1)$, or use of gas as vitreous substitute instead of BSS or air $(n=7)$. The eyes that re-detached had history of open globe injury or complex RRD/TRD with PVR. This result is similar to other studies that have shown a higher rate of re-detachment in eyes with PVR or giant tear [25, 39, 44].

Routine use of $360^{\circ}$ peripheral demarcation laser during SO insertion or removal is a controversial topic. Many studies have shown that prophylactic $360^{\circ}$ peripheral laser at the time of vitrectomy may be beneficial in lowering the risk of re-detachment $[23,30,33,38,39,41]$ showing rates from 3 to $12 \%$ compared to up to $33 \%$ in those who did not receive $360^{\circ}$ laser treatment. In the present series, $50 \%$ eyes had received $360^{\circ}$ peripheral laser treatment (anterior to the equator) at the original surgery, and 59\% underwent supplemental laser at the time of SO removal; 36 of the original 51 eyes that underwent $360^{\circ}$ peripheral retinal laser at the original PPV had additional laser at SO removal.

The reported range of hypotony (some of which was transient and recovered within weeks) following SO removal is $2-39 \%$ with the majority of studies noting it in $3-7 \%$ of eyes [25, 32, 38, 42, 43, 45]. Many studies have also noted that eyes with preoperative hypotony were significantly more likely to have persistent hypotony after SO removal. In the present study, hypotony, which was defined as IOP $<6 \mathrm{~mm} \mathrm{Hg}$ on two or more occasions, was observed in $8 \%$ of eyes after SO removal. Four of the eight of the eyes had low-IOP pre-operatively with at least one instance of IOP $<6 \mathrm{~mm} \mathrm{Hg}$, but none met the definition of hypotony. This result suggests there may be a higher risk of developing chronic hypotony after SO removal in such eyes. We discuss the increased risk of hypotony (as well as the risk of recurrent $\mathrm{RD}$ ) to patients before $\mathrm{SO}$ is removed. The eyes that developed hypotony were all open globe injured eyes; two had undergone $360^{\circ}$ retinotomy and retinectomy and one underwent $90^{\circ}$ retinotomy during previous retina surgeries.

The rate of cataract formation or progression, generally reported up to $90 \%$ [46], was seen in $68 \%$ of our patients, ranking it as our most common complication after $\mathrm{SO}$ removal. Three eyes developed a white cataract; in two eyes it was noted within a month after SO removal even though there was no history of lens touch during oil removal surgery. Overall, cataract extraction was performed in $41 \%$ of the eyes with cataract progression on an average of 335 days from date of SO removal (median: 270 days). In addition, aphakic (18) and pseudophakic (22) eyes preoperatively were not included in the percentage calculated for eyes with progression of cataract. This would also explain the lower rate of cataract progression in our cohort compared to that reported in the literature. Lastly, since cataract progression is very common after SO tamponade usage, combined phaco-cataract removal and silicone oil 
removal is frequently performed. Xu et al. reports transpupillary SO removal vs. pars plana SO removal combined with standard phaco-cataract removal. The study found that early IOP was lower with transpupillary approach however this approach does not allow management of new posterior segment pathology found intraoperatively [47].

The rate of ocular hypertension after SO removal reported in other studies is $9-16 \%$ [38, 43]. In the present study, ocular hypertension, defined as IOP $>24 \mathrm{~mm} \mathrm{Hg}$ on two or more occasions, was noted in $13 \%$ of eyes. Two eyes (2\%) needed glaucoma drainage implants after SO removal, which is lower than the 7\% reported in another study in eyes requiring glaucoma surgery after SO removal [48].

The rate of corneal complications after SO removal ranges from 3 to $11 \%$ [38, 42, 43]. In the present study, corneal complications (which included corneal oedema, band keratopathy, failed graft and non-healing epithelial defects) after SO removal occurred in $11 \%$ of eyes. One theory for progressive graft failure or corneal edema after $\mathrm{SO}$ removal in eyes with $\mathrm{SO}$ in the anterior chamber is that oil may act as a barrier against stromal hydration, and once the oil barrier is removed, the compromised endothelium permits development of corneal oedema. Of those with corneal complications, five eyes $(45 \%)$ required corneal transplant.

OCTs (pre or post) of the macula were not regularly performed in all patient in this cohort. OCT data were available in $3 \%$ of the cases with epiretinal membrane that underwent membrane peeling with SO removal. Studies have shown mild disruption of macula structure on OCT in $25-30 \%$ of all eyes and severe disruption in $75 \%$ of eyes with BCVA > 1 logMAR 6 months after PPV for RRD [49]. In addition, clinicopathological features of these epiretinal membranes after SO tamponade for RRD show these ERMs to be significantly larger than idiopathic ERMs with fragile underlying retina due to inflammation [50].

This study has limitations. As it is a retrospective study, there are many confounding variables that prevent firm conclusions regarding the various risk factors for redetachment, hypotony or the other complications. The small number of eyes with complications prevents any useful statistical analysis, rendering the conclusions observational. Finally, the time of follow-up is not standardised as some patients were lost to follow-up after few months. These limitations of retrospective consecutive case series are well recognised [51-53].

In conclusion, this large retrospective case series shows an overall improvement in VA and decrease in IOP after SO removal. Cataract progression was the most common complication. Half of the eyes with oil in the AC developed corneal oedema after oil removal; overall one-tenth of cases in the series developed corneal decompensation. Open globe injuries and PVR seemed to be associated with a higher risk of recurrent RD. We also found that eyes that developed hypotony after oil removal, either transiently or chronically had an IOP $<6 \mathrm{~mm} \mathrm{Hg}$. These important features should possibly be discussion points in pre-operative evaluation of patients undergoing oil removal. A larger cohort with a longer follow-up period will shed more light in management of such eyes.

\section{Summary}

\section{What was known before}

- Complications of eyes after silicone oil removal, including retinal re-detachment, hypotony, ocular hypertension, corneal decompensation, CME, cataract progression and others

\section{What this study adds}

- This 5-year retrospective review evaluates the characteristics, outcomes and complications of eyes after silicone oil removal. Complications after oil removal included retinal re-detachment (6.9\%), hypotony (7.9\%), ocular hypertension (12.9\%), corneal decompensation (9.9\%), CME (2\%) and cataract progression (68\%). This study showed an overall improvement in VA and decrease in IOP after oil removal.

\section{Compliance with ethical standards}

Conflict of interest M.A.Z. is a consultant for Boerhinger Ingelheim, Cell Cure, Chengdu Kanghong Biotech, Coherus Biosciences, Daiichi Sankyo, Frequency Therapeutics, Genentech/Roche, Healios KK, Iridex, Isarna Therapeutics, Makindus, Novartis Pharma AG, Ophthotech Corp., Percept Corp. The authors declare that they have no conflict of interests.

Publisher's note: Springer Nature remains neutral with regard to jurisdictional claims in published maps and institutional affiliations.

\section{References}

1. Cibis PA, Becker B, Okun E, Canaan S. The use of liquid silicone in retinal detachment surgery. Arch Ophthalmol. 1962;68:590-9.

2. Feibel RM, Blodi CF, Paul A. Cibis. MD: a pioneer of modern vitreoretinal surgery. JAMA Ophthalmol. 2013;131:1077-82.

3. Kharrat W, Turki K, Ben Amor H, et al. Use of silicone oil in vitreal hemorrhage complicating proliferated diabetic retinopathy. J Fr Ophtalmol. 2009;32:98-103.

4. Cox MS, Trese MT, Murphy PL. Silicone oil for advanced proliferative vitreoretinopathy. Ophthalmology. 1986;93:646-50.

5. Grey RH, Leaver PK. Results of silicone oil injection in massive preretinal retraction. Trans Ophthalmol Soc UK. 1977;97:238-41. 
6. Grey RH, Leaver PK. Silicone oil in the treatment of massive preretinal retraction. I. Results in 105 eyes. Br J Ophthalmol. 1979;63:355-60.

7. McCuen BW 2nd, Landers MB 3rd, Machemer R. The use of silicone oil following failed vitrectomy for retinal detachment with advanced proliferative vitreoretinopathy. Ophthalmology. 1985;92:1029-34.

8. Sell CH, McCuen BW 2nd, Landers MB 3rd, Machemer R. Longterm results of successful vitrectomy with silicone oil for advanced proliferative vitreoretinopathy. Am J Ophthalmol. 1987;103:24-28.

9. Yeo JH, Glaser BM, Michels RG. Silicone oil in the treatment of complicated retinal detachments. Ophthalmology. 1987;94:1109-13.

10. Azen SP, Scott IU, Flynn HW Jr, et al. Silicone oil in the repair of complex retinal detachments. A prospective observational multicenter study. Ophthalmology. 1998;105:1587-97.

11. Castellarin A, Grigorian R, Bhagat N, Del Priore L, Zarbin MA. Vitrectomy with silicone oil infusion in severe diabetic retinopathy. Br J Ophthalmol. 2003;87:318-21.

12. de Juan E Jr., Hardy M, Hatchell DL, Hatchell MC. The effect of intraocular silicone oil on anterior chamber oxygen pressure in cats. Arch Ophthalmol. 1986;104:1063-4.

13. Higuchi A, Yamada H, Kawai E, et al. Vitrectomy for proliferative diabetic retinopathy. Nippon Ganka Gakkai Zasshi. 2005;109:134-134.

14. Hoerauf H, Roider J, Bopp S, Lucke K, Laqua H. Endotamponade with silicon oil in severe proliferative retinopathy with attached retina. Ophthalmole. 1995;92:657-62.

15. Szurman PR, S; Grisanti, S. Primary silicone oil tamponade in the management of severe intraocular foreign body injuries: an 8-year follow-up. Retina. 2007;3:304-11.

16. Vitrectomy with silicone oil or sulfur hexafluoride gas in eyes with severe proliferative vitreoretinopathy: results of a randomized clinical trial. Silicone Study Report 1. Arch Ophthalmol. 1992;110:770-9.

17. Abrams GW, Azen SP, McCuen BW 2nd, Flynn HW Jr., Lai MY, Ryan SJ. Vitrectomy with silicone oil or long-acting gas in eyes with severe proliferative vitreoretinopathy: results of additional and long-term follow-up. Silicone Study report 11. Arch Ophthalmol. 1997;115:335-44.

18. Chylack LT Jr., Leske MC, McCarthy D, Khu P, Kashiwagi T, Sperduto R. Lens opacities classification system II (LOCS II). Arch Ophthalmol. 1989;107:991-7.

19. de Juan E Jr., McCuen B, Tiedeman J. Intraocular tamponade and surface tension. Surv Ophthalmol. 1985;30:47-51.

20. Heimann K, Dahl B, Dimopoulos S, Lemmen KD. Pars plana vitrectomy and silicone oil injection in proliferative diabetic retinopathy. Graefe's Arch Clin Exp Ophthalmol. 1989;227:152-6.

21. Roca JA, Wu L, Berrocal M, et al. Un-explained visual loss following silicone oil removal: results of the Pan American Collaborative Retina Study (PACORES) Group. Int J Retin Vitreous. 2017;3:26.

22. Lam RF, Cheung BT, Yuen CY, Wong D, Lam DS, Lai WW. Retinal redetachment after silicone oil removal in proliferative vitreoretinopathy: a prognostic factor analysis. Am J Ophthalmol. 2008;145:527-33.

23. Pavlovic S, Dick B, Schmidt KG, Tomic Z, Latinovic S. Long-term outcome after silicone oil removal. Ophthalmole. 1995;92:672-6.

24. Ramezani A, Ahmadieh H, Rozegar A, et al. Predictors and outcomes of vitrectomy and silicone oil injection in advanced diabetic retinopathy. Korean J Ophthalmol. 2017;31:217-29.

25. Bassat IB, Desatnik H, Alhalel A, Treister G, Moisseiev J. Reduced rate of retinal detachment following silicone oil removal. Retina. 2000;20:597-603.

26. Krzystolik MG, D'Amico DJ. Complications of intraocular tamponade: silicone oil versus intraocular gas. Int Ophthalmol Clin. 2000;40:187-200.
27. Falkner CI, Binder S, Kruger A. Outcome after silicone oil removal. Br J Ophthalmol. 2001;85:1324-7.

28. Jawad M, Khan B, Shah MA, Qayum I, Aftab M. Changes of intraocular pressure in vitrectomised eyes after removal of silicone oil. J Ayub Med Coll Abbottabad. 2016;28:327-30.

29. Moisseiev J, Barak A, Manaim T, Treister G. Removal of silicone oil in the management of glaucoma in eyes with emulsified silicone. Retina. 1993;13:290-5.

30. Avitabile T, Longo A, Lentini G, Reibaldi A. Retinal detachment after silicone oil removal is prevented by 360 degrees laser treatment. Br J Ophthalmol. 2008;92:1479-82.

31. Casswell AG, Gregor ZJ. Silicone oil removal. I. The effect on the complications of silicone oil. Br J Ophthalmol. 1987;71:893-7.

32. Casswell AG, Gregor ZJ. Silicone oil removal. II. Operative and postoperative complications. Br J Ophthalmol. 1987;71: 898-902.

33. Falkner-Radler CI, Smretschnig E, Graf A, Binder S. Outcome after silicone oil removal and simultaneous 360 degrees endolaser treatment. Acta Ophthalmol. 2011;89:e46-51.

34. Hutton WL, Azen SP, Blumenkranz MS, et al. The effects of silicone oil removal. Silicone Study Report 6. Arch Ophthalmol. 1994;112:778-85.

35. Jonas JB, Knorr HL, Rank RM, Budde WM. Retinal redetachment after removal of intraocular silicone oil tamponade. Br J Ophthalmol. 2001;85:1203-7.

36. Kapran Z, Acar N. Removal of silicone oil with 25-gauge transconjunctival sutureless vitrectomy system. Retina. 2007;27:1059-64.

37. Scholda C, Egger S, Lakits A, Walch K, von Eckardstein E, Biowski R. Retinal detachment after silicone oil removal. Acta Ophthalmol Scand. 2000;78:182-6.

38. Al-Wadani SF, Abouammoh MA, Abu El-Asrar AM. Visual and anatomical outcomes after silicone oil removal in patients with complex retinal detachment. Int Ophthalmol. 2014;34:549-56.

39. Dhalla K, Kapesa I, Odouard C. Incidence and risk factors associated with retinal redetachment after silicone oil removal in the African population. Int Ophthalmol. 2017;37:583-9.

40. Ghoraba HH, Elgouhary SM, Mansour HO. Silicone oil reinjection without macular buckling for treatment of recurrent myopic macular hole retinal detachment after silicone oil removal. J Ophthalmol. 2014;2014:434272.

41. Tavares RLP, Nobrega MJ, Nobrega FAJ, De Novelli FJ, De Oliveira CAC. Timing and outcomes after silicone oil removal in proliferative vitreoretinopathy: a retrospective clinical series. Int J Retina Vitreous. 2015;1:2.

42. Zafar S, Bokhari SA, Kamil Z, Shakir M, Rizvi SF, Memon GM. Outcomes of silicone oil removal. J Coll Physicians Surg Pak. 2013;23:476-9.

43. Moisseiev E, Ohana O, Gershovitch L, Barak A. Visual prognosis and complications following silicone oil removal. Eur J Ophthalmol. 2013;23:236-41.

44. Teke MY, Balikoglu-Yilmaz M, Yuksekkaya $P$, et al. Surgical outcomes and incidence of retinal redetachment in cases with complicated retinal detachment after silicone oil removal: univariate and multiple risk factors analysis. Retina. 2014;34:1926-38.

45. Kim SW, Oh J, Yang KS, Kim MJ, Rhim JW, Huh K. Risk factors for the development of transient hypotony after silicone oil removal. Retina. 2010;30:1228-36.

46. Feng H, Adelman RA. Cataract formation following vitreoretinal procedures. Clin Ophthalmol. 2014;8:1957-65.

47. Xu W, Cheng W, Zhuang H, Guo J, Xu G. Safety and efficacy of transpupillary silicone oil removal in combination with microincision phacoemulsification cataract surgery: comparison with 23-gauge approach. BMC Ophthalmol. 2018;18:200.

48. Wesolek-Czernik A. The influence of silicone oil removal on intraocular pressure. Klin Oczna. 2002;104:219-21. 
49. Saber EE, Bayoumy ASM, Elmohamady MN, Faramawi HM. Macular microstructure and visual acuity after macula-off retinal detachment repair by 23 -gauge vitrectomy plus silicone endotamponade. Clin Ophthalmol. 2018;12:2005-13.

50. Tanaka Y, Toyoda F, Shimmura-Tomita M, et al. Clinicopathological features of epiretinal membranes in eyes filled with silicone oil. Clin Ophthalmol. 2018;12:1949-57.
51. DiLoreto DA Jr., Bressler NM, Bressler SB, Schachat AP. Use of best and final visual acuity outcomes in ophthalmological research. Arch Ophthalmol. 2003;121:1586-90.

52. Jabs DA. Improving the reporting of clinical case series. Am J Ophthalmol. 2005;139:900-5.

53. Zeger SL, Liang KY. Longitudinal data analysis for discrete and continuous outcomes. Biometrics. 1986;42:121-30. 